\title{
Visible and near-infrared excitation spectra from the neptunyl ion doped into a uranyl tetrachlo- ride lattice
}

Beau J. Barker, John M. Berg, Stosh A. Kozimor, Nicholas R. Wozniak and Marianne P. Wilkerson*

Los Alamos National Laboratory, Post Office Box 1663 Mail Stop J514, Los Alamos, NM 87545, USA

\begin{abstract}
Visible and near-infrared illumination induces 5f-5f and ligand-to-metal charge-transfer (LMCT) transitions of the neptunyl tetrachloride anion in polycrystalline $\mathrm{Cs}_{2} \mathrm{U}(\mathrm{Np}) \mathrm{O}_{2} \mathrm{Cl}_{4}$, and results in near-infrared luminescence from the second electronically excited state to the ground state. This photoluminescence is used as a detection method to collect excitation spectra throughout the near-infrared and visible regions. The excitation spectra of LMCT transitions in excitation spectra were identified in previous work. Here the measurement and analysis is extended to include both LMCT and intra-5f transitions. The results manifest variation in structural properties of the neptunium-oxo bond among the lowlying electronic states. Vibronic intensity patterns and energy spacings are used to compare bond lengths and vibrational frequencies in the excited states, confirming significant characteristic differences between those excited by $5 \mathrm{f}-5 \mathrm{f}$ transitions from those due to LMCT transitions. Results are compared with recently published SO-RASPT2 calculations of $\left[\mathrm{NpO}_{2} \mathrm{Cl}_{4}\right]^{2-}$.
\end{abstract}

\section{$L A-U R-15-26413$}

Keywords: actinide, electronic structure, excitation spectrum, intra-5f, ligand-to-metal charge-transfer, neptunyl

\section{Introduction}

Electronic structure modeling of open-shell actinyl ions has been hindered by the high number and density of valence states characteristic of these systems and by the relative paucity of experimental data for validation of theoretical results. ${ }^{1-11}$ Typically transitions between these electronic states span a broad energy range from the near-infrared to the ultraviolet. The transitions are described as either $5 \mathrm{f}-5 \mathrm{f}$ or ligand-to-metal charge-transfer (LMCT). Optical studies have been conducted on $5 \mathrm{f}^{1}$ uranium(V) dioxo molecules, which contain the simplest open-shell ground state electronic configuration, [Rn]5 $\mathrm{f}^{1}$, but stable $\mathrm{U}(\mathrm{V})$ compounds are limited in number due to disproportionation of $\mathrm{U}(\mathrm{V})$ to $\mathrm{U}(\mathrm{IV})$ and $\mathrm{U}(\mathrm{VI}) .^{12,13}$ The neptunyl ion, $\mathrm{Np}(\mathrm{VI}) \mathrm{O}_{2}{ }^{2+}$, is perhaps a more attractive member of the open-shell family for spectroscopic analyses because it can form stable compounds that are isostructural with those of the wellstudied, closed-shell uranyl ion $\mathrm{U}(\mathrm{VI}) \mathrm{O}_{2}{ }^{2+}$. This latter property enables $\mathrm{Np}(\mathrm{VI}) \mathrm{O}_{2}{ }^{2+}$ to be doped into 
stable chemical environments of uranyl compounds and studied as a dilute component in a host that is optically transparent in the near-infrared. ${ }^{14-20}$ The neptunyl tetrachloride ion $\left[\mathrm{NpO}_{2} \mathrm{Cl}_{4}\right]^{2-}$ doped into a $\mathrm{Cs}_{2} \mathrm{UO}_{2} \mathrm{Cl}_{4}$ host has been the subject of several studies largely for these reasons, and because the chloride ligands introduce no internal ligand vibrations to complicate spectral interpretation.

Near-infrared absorption spectra were first reported by Stafsudd in 1969, and later by Gorshkov. ${ }^{19,20}$ Subsequently, Denning and co-workers recorded polarized absorption spectra at $4.2 \mathrm{~K},{ }^{14,15}$ as well as magnetic circular dichroism spectra, and Zeeman effect measurements, and then used parameterized ligand field theory to assign ten electronically excited transitions and associated vibronic structure in the region between 600-22,000 $\mathrm{cm}^{-1}$. In this work, we adhere to Denning's convention of labeling excited electronic states as Roman numerals $\mathbf{I}$ through $\mathbf{X}$ and the ground electronic state as $\mathbf{0 .}$

In principle, photoluminescence excitation and absorption spectra measure similar information concerning electronic structure, but luminescence spectroscopy allows signals from impurities to be excluded more effectively and is easier to employ on small, irregularly shaped crystals. Dilution of the $\left[\mathrm{NpO}_{2} \mathrm{Cl}_{4}\right]^{2-}$ dianion into a $\mathrm{Cs}_{2} \mathrm{UO}_{2} \mathrm{Cl}_{4}$ host inhibits potential self-quenching of the lower energy photoemission. ${ }^{16,17}$ Near-infrared photoluminescence of $\left[\mathrm{NpO}_{2} \mathrm{Cl}_{4}\right]^{2-}$ from the electronic state II to the ground state $\mathbf{0}$ was first reported by Wilkerson and Berg using $\mathrm{Cs}_{2} \mathrm{U}(\mathrm{Np}) \mathrm{O}_{2} \mathrm{Cl}_{4}$ crystals cooled to $75 \mathrm{~K}^{16}$ This study revealed the feasibility of using luminescence to detect valence electronic transitions of open-shell actinide molecules in the solid state. Later, Wilkerson and Berg used photoluminescence from $\mathbf{I I} \rightarrow \mathbf{0}$ to record an excitation spectrum of $\mathrm{Cs}_{2} \mathrm{U}(\mathrm{Np}) \mathrm{O}_{2} \mathrm{Cl}_{4}$ between 13,200 and 21,275 $\mathrm{cm}^{-1}{ }^{18}$ Transitions $\mathbf{0} \rightarrow$ IV through VII, IX and X, each characterized by Denning as LMCT, were identified in this spectral region, and the vibronic transitions in the emission and excitation spectra were assigned with the aid of Denning's absorption data. ${ }^{14,15}$

This paper presents a comprehensive report of photoluminescence excitation spectra of transitions over a broader range and of higher quality from the ground electronic state to excited electronic states throughout the near-infrared and visible spectral regions $\left(6,585-24,000 \mathrm{~cm}^{-1}\right)$ using the near-infrared photoluminescence from state II to the ground state $\mathbf{0}$ as a sensitive means of detection. We discuss the significance of observed vibronic progressions in the neptunyl symmetric stretch, and present several low-intensity previously unobserved features belonging to states II and III that suggest new information concerning the nature of the neptunium-oxo bond. We apply a standard approach to modeling the intensity of vibronic progressions in the neptunyl symmetric stretch in both $5 f-5 f$ and LMCT transitions to derive neptunium-oxo bond length changes upon excitation into excited electronic states. We compare these results with SO-RASPT2 (restricted-active-space perturbation theory with spin-orbit coupling) calculations reported in the literature. ${ }^{10,14-23}$ 


\section{Experimental}

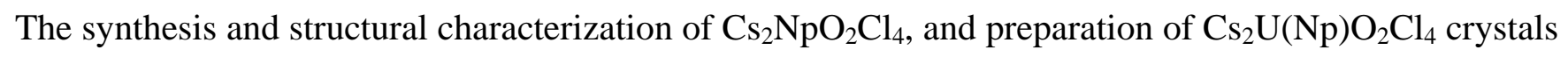
are described elsewhere. ${ }^{16-18}$ The ratio of $\mathrm{Np}: \mathrm{U}$ is $\sim 3 \%$, based upon the relative concentrations of $\mathrm{Np}$ and $U$ dissolved in the parent solution. The polycrystalline needles are $\sim 5 \mathrm{~mm}$ long and $\sim 1-2 \mathrm{~mm}$ wide.

The excitation source used for this study is a tunable optical parametric oscillator (Continuum Panther) pumped by a pulsed Nd:YAG laser (Continuum Surelight II-10) operating at $10 \mathrm{~Hz}$. The OPO has a spectral bandwidth of $\sim 5 \mathrm{~cm}^{-1}$. The laser beam was attenuated to $<5 \mathrm{~mJ}$ and not focused prior to interaction with the sample. A portion of the laser output signal was monitored with a pyroelectric detector (Molectron J4-09) in order to normalize the intensity of the excitation spectra to the intensity of the laser. Excitation spectra were calibrated by dispersing scattered laser light through a calibrated monochromator. The monochromator itself was calibrated using the atomic emission lines from a $\mathrm{Kr}$ lamp. ${ }^{24}$ Photoluminescence from the sample was collected at $90^{\circ}$ from the excitation laser and dispersed using a $300 \mathrm{~mm}$ focal length spectrograph (Acton Research Corporation SpectraPro-300i) with a 600 line/mm grating blazed at $1.0 \mu \mathrm{m}$. For excitation spectra, a slit width of $0.15 \mathrm{~mm}$ was used, and the resolution of emission was $\sim 5 \mathrm{~cm}^{-1}$. Photoluminescence was detected using a photomultiplier tube (PMT) (Hamamatsu R5509-72). The error in the reported peak positions from the excitation spectrum is $\pm 5 \mathrm{~cm}^{-1}$.

\section{Results and Discussion}

The $\left[\mathrm{NpO}_{2} \mathrm{Cl}_{4}\right]^{2-}$ anion is centrosymmetric with pseudo- $D_{4 h}$ symmetry. ${ }^{14,15,17}$ Electric dipole transitions between $5 \mathrm{f}$ and low-lying LMCT electronic states are parity forbidden in $D_{4 h}$, but may be allowed through magnetic dipole or electric quadrupole mechanisms, or can be electric dipole allowed if coupled with excitation or de-excitation of ungerade molecular vibrations. ${ }^{6,14,15,17}$ The combination of electricdipole forbidden pure electronic transitions and vibronic coupling to ungerade modes can result in stronger vibronic sidebands. The $\left[\mathrm{NpO}_{2} \mathrm{Cl}_{4}\right]^{2-}$ anion has eleven vibrational modes, including a symmetric stretch $\left(v_{1}\right)$, an asymmetric $\mathrm{O}=\mathrm{Np}=\mathrm{O}$ stretch $\left(v_{2}\right)$, the neptunyl bend $\left(v_{3}\right)$, and four asymmetric Np$\mathrm{Cl}$ stretches and bends. In particular, the totally symmetric $\mathrm{O}=\mathrm{Np}=\mathrm{O}$ stretching mode $\left(v_{1}\right)$ has a significant role in spectroscopic analysis if the metal-oxygen bond distance changes upon excitation. The reported symmetries and energies of these modes in the ground electronic state are listed in Table 1. Identification of vibronic transitions involving these modes in the excited states is greatly aided by the reasonable assumption that the frequencies will be similar to those in the ground state.

In this paper we retain the labeling scheme previously used by Denning to identify the electronic states. ${ }^{14,15}$ Each electronic state is identified by a Roman numeral stated in bold, starting with $\mathbf{0}$ for the ground state, I for the first excited state, II for the second excited state, etc. Table 2 shows a summary 
for the experimentally derived energy, the $v_{1}$ vibrational frequency for each electronic state compared with the results from the SO-RASPT2 calculations. ${ }^{10,14,15}$ Table 3 shows energies and vibrational frequencies of $v_{1}$ and $v_{2}$ for states II-VI which were derived from our excitation spectrum. The average energy of $v_{1}$ for the LMCT states is $\sim 709 \mathrm{~cm}^{-1}$, and the average energy of $v_{1}$ for the $5 \mathrm{f} \delta$ and $\phi$ states $(\mathbf{0}$ to III) is measurably higher $\sim 807 \mathrm{~cm}^{-1}$.

The excitation spectrum of $\mathrm{Cs}_{2} \mathrm{U}(\mathrm{Np}) \mathrm{O}_{2} \mathrm{Cl}_{4}$ crystals cooled to $75 \mathrm{~K}$ is shown in Figure 1 . The region between 7,460 and $24,000 \mathrm{~cm}^{-1}$ was collected by monitoring the intensity of $\mathbf{I I} \rightarrow \mathbf{0}$ at $6,880 \mathrm{~cm}^{-1}$ while scanning the excitation laser. The features between $6,585-7,460 \mathrm{~cm}^{-1}$ were collected by placing a 1,500 $\mathrm{nm}\left(6,667 \mathrm{~cm}^{-1}\right)$ long pass filter in front of the monochromator with the diffraction grating in its zerothorder position, excluding the $\mathbf{I I} \rightarrow \mathbf{0}$ origin at $6,880 \mathrm{~cm}^{-1}$ but allowing light from vibronic emission transitions with wavelengths longer than $1,500 \mathrm{~nm}$ to reach the PMT.

Overall, the number of peaks, the peak energies and relative intensities in the excitation spectrum are in reasonable agreement with those in the absorption spectra reported by Denning from crystals cooled to 4.2 K, but new vibronic assignments are made involving the $v_{1}$ mode for transitions to states II and III. ${ }^{14,15}$ In comparison with solution spectra of $\mathrm{U}(\mathrm{V}) \mathrm{O}_{2}{ }^{+}$compounds, the intra- $5 f$ transitions of the more oxidizing $\mathrm{NpO}_{2}{ }^{2+}$ are predictably lower in energy as a result of the higher positive charge on $\mathrm{Np}(\mathrm{VI}) .^{12,13}$ A superscript following the symbol $v$ signifies the electronic state to which the vibronic peak is associated.

Figure 1. Laser-induced excitation spectrum between $6,585-24,000 \mathrm{~cm}^{-1}$ recorded while monitoring luminescence from the $\mathbf{I I} \rightarrow \mathbf{0}$ transition $\left(6,880 \mathrm{~cm}^{-1}\right)$ of $\mathrm{Cs}_{2} \mathrm{U}(\mathrm{Np}) \mathrm{O}_{2} \mathrm{Cl}_{4}$ at $75 \mathrm{~K}$.

The portion of the excitation spectrum between 6,585 and $10,000 \mathrm{~cm}^{-1}$ is shown in Figure 2. Features in this region involve $\mathbf{0} \rightarrow$ II and $\mathbf{0} \rightarrow$ III electronic transitions. The intense and narrow transition at 6,880 $\mathrm{cm}^{-1}$ is assigned as $\mathbf{0} \rightarrow \mathbf{I I}$ origin, in agreement with Denning's reported value of $6,880.4 \mathrm{~cm}^{-1}$. The assignment of this electronic transition is supported by the presence of vibronic hot bands at $\sim 6,769 \mathrm{~cm}^{-1}$ and $\sim 6,837 \mathrm{~cm}^{-1}$. These transitions are lower in energy than the origin by approximately the energies of the infrared-active ground state neptunium-chloride modes $\mathbf{v}_{\mathbf{8}}^{\mathbf{0}}, \mathbf{v}_{\mathbf{9}}^{\mathbf{0}}\left(100-130 \mathrm{~cm}^{-1}\right)$ and the lattice modes $\left(0-80 \mathrm{~cm}^{-1}\right)$, and we assign these modes as $\mathbf{0}+\mathbf{v}_{\mathbf{8 / 9}}^{\mathbf{0}} \rightarrow \mathbf{I I}$ and $\mathbf{0}+$ lattice modes $\rightarrow$ II, respectively. The transitions $0-80 \mathrm{~cm}^{-1}$ and $100-130 \mathrm{~cm}^{-1}$ higher in energy than origin II and near mirror images of the hot bands are assigned to $\mathbf{0} \rightarrow \mathbf{I I}+$ lattice modes $\left(6,923 \mathrm{~cm}^{-1}\right)$ and $\mathbf{0} \rightarrow \mathbf{I I}+\mathbf{v}_{\mathbf{8} / \mathbf{9}}^{\mathbf{I I}}\left(7,009 \mathrm{~cm}^{-1}\right)$. The peaks 
240-285 $\mathrm{cm}^{-1}$ above $\mathbf{0} \rightarrow$ II are assigned to vibronic structure built on the neptunium-chloride stretching mode, $\mathbf{0} \rightarrow \mathbf{I I}+\mathbf{v}_{{ }_{\mathbf{6}}}^{\text {II }}\left(7,126 \mathrm{~cm}^{-1}\right)$, and the neptunium-oxo bending mode, $\mathbf{0} \rightarrow \mathbf{I I}+\mathbf{v}^{\text {II }}\left(7,157 \mathrm{~cm}^{-1}\right)$.

The intense and sharp transition at 7,801 $\mathrm{cm}^{-1}, 921 \mathrm{~cm}^{-1}$ higher in energy than $\mathbf{0} \rightarrow \mathbf{I I}$, could be assigned to either $\mathbf{0} \rightarrow \mathbf{I I}+\mathbf{V}_{2}{ }_{2}$ or to $\mathbf{0} \rightarrow$ III. To unambiguously assign this peak, we compared our excitation spectrum to an absorption spectrum reported by Stone in his Ph.D. thesis (advisor Robert Denning), which is not published in the open literature. ${ }^{25}$ In this investigation, a second absorption spectrum was recorded using ${ }^{18} \mathrm{O}$ enriched $\mathrm{NpO}_{2}{ }^{2+}$. Isotopic substitution allows vibronic structure belonging to neptunium-oxo vibrational modes to be identified because they are shifted to lower energy while the energies of pure electronic transitions and neptunium-chloride vibronic transitions are only slightly perturbed. Stone was able to assign the peak at $7,801 \mathrm{~cm}^{-1}$ as $\mathbf{I I}+\boldsymbol{v}_{2}^{\text {II }}$ because in was blue-shifted by $\sim 44 \mathrm{~cm}^{-1}$ after ${ }^{18} \mathrm{O}$ substitution.

A weak feature at $7,706 \mathrm{~cm}^{-1}$ is assigned as $\mathbf{0} \rightarrow \mathbf{I I}+\boldsymbol{v}_{\mathbf{1}}$. The energy difference from the $\mathbf{0} \rightarrow \mathbf{I I}$ origin to this peak gives a value of $826 \mathrm{~cm}^{-1}$ for $v^{\text {II }}{ }_{1}$. This value is measurably larger than $\mathbf{v}_{\mathbf{1}}{ }_{1}$ in the ground electronic state. The weak but sharp peak in our excitation spectrum at $8,613 \mathrm{~cm}^{-1}$ is assigned as $\mathbf{0} \rightarrow$ II + $\boldsymbol{v}_{\mathbf{2}}^{\text {II }}+\boldsymbol{v}^{\text {II }}{ }_{1}$. This outcome gives a frequency of $812 \mathrm{~cm}^{-1}$ for $\boldsymbol{v}_{1}{ }_{1}$ from the energy gap between $\mathbf{0} \rightarrow$ II + $\mathbf{V}_{2}$ and $\mathbf{0} \rightarrow$ II $+v^{\text {II }}{ }_{2}+v^{\text {II }}$, and indicates that the combination band has some significant anharmonicity. The combination $\mathbf{v}_{\mathbf{1}}^{\mathbf{0}}+\mathbf{v}_{\mathbf{2}}^{\mathbf{0}}$ band in the ground electronic state from Denning's absorption spectra shows a similar anharmonicity when compared to the sum of the energies of $\mathbf{v}_{\mathbf{1}}^{\mathbf{0}}$ and $\mathbf{v}_{\mathbf{2}}^{\mathbf{0}}$ measured directly. Neither the $7,706 \mathrm{~cm}^{-1}$ nor the $8,613 \mathrm{~cm}^{-1}$ peak appears in either the published spectra of Denning et al. or Stone's thesis. This result is not entirely surprising, however, because the peaks are quite weak and may well have been obscured by baseline noise in their absorption spectra.

The set of strong, partially resolved features at 7,989, 8,020, 8,118, and 8,143 $\mathrm{cm}^{-1}$, appear both here and in Stone's spectra. These peaks shifted very little with Stone's ${ }^{18} \mathrm{O}$ substitution, and consequently they were assigned as vibronic transitions involving excitation of chlorine modes with the upper states being III $+v^{\text {III }}{ }_{\mathbf{8}}$, III $+v^{\text {III }}{ }_{9}$, III $+v^{\text {III }}{ }_{6}$, and III $+v^{\text {III }}{ }_{3}$, respectively. No feature assignable as the $\mathbf{0} \rightarrow$ III transition can be identified in our excitation spectrum (see Figure 2), nor in the absorption spectra recorded by Stone or Denning. Origin III energy can be estimated by assuming that the $\mathbf{v}_{\mathbf{8}}^{\text {III }}, \boldsymbol{v}_{\mathbf{9}}^{\text {III }}, \boldsymbol{v}^{\text {III }}{ }_{\mathbf{6}}$, and $v^{\text {III }}{ }_{3}$ vibronic modes have energies similar to those of the ground vibrational state. Making this assumption places origin III at $\sim 7,875 \mathrm{~cm}^{-1} \pm 20 \mathrm{~cm}^{-1}$, in agreement with Denning's estimate of $7,890 \mathrm{~cm}^{-1}$.

The doublets at 8,797 and $8,830 \mathrm{~cm}^{-1}$, and at 9,593 and 9,635 $\mathrm{cm}^{-1}$ are $\sim 800 \mathrm{~cm}^{-1}$ apart, suggestive of progressions in $v_{1}$. The first pair of peaks was observed but not assigned by Denning, and the second set 
of higher energy peaks is outside the energy of their published spectrum. In Denning's spectra, the lower energy peaks show polarization behavior identical to other vibronic features belong to state III confirming that these peaks belong to state III. The lower energy peak in the first pair $\left(8,797 \mathrm{~cm}^{-1}\right)$ is $\sim 922 \mathrm{~cm}^{-1}$ above the inferred position of the $\mathbf{0} \rightarrow$ III origin, so it could be assigned as $\mathbf{0} \rightarrow$ III $+\mathbf{v}^{\text {III }}{ }_{2}$. It is also 808 $\mathrm{cm}^{-1}$ above the peak assigned as $\mathbf{0} \rightarrow$ III $+\boldsymbol{v}^{\mathrm{III}}\left(7,989 \mathrm{~cm}_{\mathbf{8}}^{-1}\right)$, making $\mathbf{0} \rightarrow \mathbf{I I I}+\boldsymbol{v}_{\mathbf{8}}^{\text {III }}+\boldsymbol{v}^{\text {III }}{ }_{\mathbf{1}}$ a plausible assignment as well. The peak at $9,593 \mathrm{~cm}^{-1}$ is $796 \mathrm{~cm}^{-1}$ higher in energy, and is assigned as $\mathbf{0} \rightarrow$ III + $\boldsymbol{v}_{8}^{\text {III }}+2 v^{\text {III }}{ }_{1}$ or $\mathbf{0} \rightarrow$ III $+v^{\text {III }}{ }_{2}+v^{\text {III }}$. The feature at $8,830 \mathrm{~cm}^{-1}$ is $810 \mathrm{~cm}^{-1}$ above the III $+v^{\text {III }}$ peak and is assigned as III $+v^{\text {III }}{ }_{9}+v^{\text {III }}{ }_{1}$, and the feature at $9,635 \mathrm{~cm}^{-1}$ is an additional $805 \mathrm{~cm}^{-1}$ higher in energy and is assigned as III $+v^{\text {III }}{ }_{9}+2 v^{\text {III }}{ }_{1}$. Using these assignments, the average energy for the first two quanta of the neptunium-oxo symmetric stretch in state III $\left(v^{\mathrm{III}}\right)$, is $805 \mathrm{~cm}^{-1}$, close to the observed $\boldsymbol{v}_{1}^{0}$ frequency in the ground state.

Figure 2. Laser-induced excitation spectrum between $6,585-10,000 \mathrm{~cm}^{-1}$ recorded while monitoring luminescence from the $\mathbf{I I} \rightarrow \mathbf{0}$ transition of $\mathrm{Cs}_{2} \mathrm{U}(\mathrm{Np}) \mathrm{O}_{2} \mathrm{Cl}_{4}$ at $75 \mathrm{~K}$.

The region of the excitation spectrum between 12,800 and $15,000 \mathrm{~cm}^{-1}$ is shown in Figure 3 , and peak assignments and energies of each transition identified in our excitation spectrum are provided in Table 5. The narrow feature observed at $13,248 \mathrm{~cm}^{-1}$ is assigned to the origin of $\mathbf{0} \rightarrow \mathbf{I V}$. This value is somewhat lower in energy than reported by Denning $\left(13,264.9 \mathrm{~cm}^{-1}\right)$ and Stone $\left(13,259.0 \mathrm{~cm}^{-1}\right)$. Our assignment of $\mathbf{0} \rightarrow \mathbf{I V}$ is supported by the presence of vibronic hot bands at $\sim 13,133 \mathrm{~cm}^{-1}$ and $13,210 \mathrm{~cm}^{-1}$, which are $115 \mathrm{~cm}^{-1}$ and $38 \mathrm{~cm}^{-1}$ lower in energy, and we assign these modes as $\mathbf{0}+\mathbf{v}_{\mathbf{8} / \mathbf{9}}^{\mathbf{0}} \rightarrow \mathbf{I V}$ and $\mathbf{0}+$ lattice modes $\rightarrow \mathbf{I V}$, respectively. The intense peaks at 13,282 and 13,352 $\mathrm{cm}^{-1}$ are assigned to $\mathbf{0} \rightarrow$ $\mathbf{I V}+$ lattice modes and $\mathbf{0} \rightarrow \mathbf{I V}+\mathbf{v}_{\mathbf{8 / 9}}^{\mathbf{I V}}$. The peaks at 13,486 and 13,497 $\mathrm{cm}^{-1}$ are $\sim 240-285 \mathrm{~cm}^{-1}$ higher in energy than $\mathbf{0} \rightarrow \mathbf{I V}$ and are assigned to $\mathbf{0} \rightarrow \mathbf{I V}+\mathbf{v}^{\mathbf{I V}}{ }_{\mathbf{6}}$, and $\mathbf{0} \rightarrow \mathbf{I V}+\mathbf{v}^{\mathbf{I V}}$, respectively. The transitions measured at 13,968 and $14,008 \mathrm{~cm}^{-1}$ are assigned as $\mathbf{0} \rightarrow \mathbf{I V}+\mathbf{v}_{\mathbf{1}}^{\mathbf{I V}}$ and $\mathbf{0} \rightarrow \mathbf{I V}+\mathbf{v}_{\mathbf{2}}^{\mathbf{I V}}$, giving frequencies for $\mathbf{v}^{\mathbf{I V}}$ and $\mathbf{v}^{\mathbf{I V}}$ of $720 \mathrm{~cm}^{-1}$ and $760 \mathrm{~cm}^{-1}$, respectively. These agree with those observed in Denning's spectra. Denning reported the frequency of $\mathbf{I V}+\mathbf{v}^{\mathbf{I V}}{ }_{\mathbf{2}}+\mathbf{v}_{\mathbf{1}}^{\mathbf{I V}}$ at $710.9 \mathrm{~cm}^{-1}$ above the origin IV $+v^{\mathbf{I V}}{ }_{2}$, attributing the lower $\boldsymbol{v}^{\mathbf{I V}}{ }_{\mathbf{1}}$ frequency in the combination band to anharmonic coupling. ${ }^{15}$ We derive a corresponding value of $718 \mathrm{~cm}^{-1}$ from the position of the assigned $\mathbf{0} \rightarrow \mathbf{I V}+\mathbf{v}^{\mathbf{I V}}{ }_{\mathbf{2}}+\mathbf{v}^{\mathbf{I V}}{ }_{\mathbf{1}}$ peak at $14,726 \mathrm{~cm}^{-1}$. Other combination bands involving the chlorine modes, such as the peak at $14,074 \mathrm{~cm}^{-1}$ assigned as $\mathbf{I V}+\mathbf{v}_{\mathbf{8 / 9}}^{\mathbf{I V}}+\mathbf{v}^{\mathbf{I V}}$, yield values for $\boldsymbol{v}^{\mathbf{I V}}{ }_{\mathbf{1}}$ that are indistinguishable from the progression built on the electronic origin. The energies of $\mathbf{v}_{1}^{\mathbf{I V}}$ and $\boldsymbol{v}^{\mathbf{I V}}{ }_{2}$ are significantly lower than the energies of these 
modes in the ground state, consistent with the charge transfer nature of $\mathbf{0} \rightarrow \mathbf{I V}$ and consequent weakening of the neptunium-oxo bonds in the excited state.

Figure 3. Laser-induced excitation spectrum between 12,800-15,000 $\mathrm{cm}^{-1}$ recorded while monitoring luminescence from the $\mathbf{I I} \rightarrow \mathbf{0}$ transition of $\mathrm{Cs}_{2} \mathrm{U}(\mathrm{Np}) \mathrm{O}_{2} \mathrm{Cl}_{4}$ at $75 \mathrm{~K}$. The absence of spectral data between $\sim 14,100-14,400 \mathrm{~cm}^{-1}$ is due to very low laser power at these energies.

The third region of the excitation spectrum between $15,000-18,000 \mathrm{~cm}^{-1}$ is shown in Figure 4. This region contains vibronic transitions from the ground state to excited states $\mathbf{V}$ and $\mathbf{V I}$. We focus on features assigned to $\mathbf{0} \rightarrow \mathbf{V}$ and its vibronic sidebands, as excitation spectra of VI-X have been reported elsewhere. ${ }^{18}$ The energy of $\mathbf{0} \rightarrow \mathbf{V}$ measured at $\sim 15,402 \mathrm{~cm}^{-1}$ agrees with the energy reported by Denning at $15,406.4 \mathrm{~cm}^{-1}$. The assignment of this electronic origin is supported by the presence of vibronic hot bands at 15,355 and 15,284 $\mathrm{cm}^{-1}$ which are lower in energy than the origin by the energies of lattice modes $\left(0-80 \mathrm{~cm}^{-1}\right)$, and neptunium-chloride modes $\mathbf{v}_{\mathbf{8}}^{\mathbf{0}}$ and $\mathbf{v}_{\mathbf{9}}^{\mathbf{0}}\left(100-130 \mathrm{~cm}^{-1}\right)$. Therefore, we assign these transitions as $\mathbf{0}+$ lattice modes $\rightarrow \mathbf{V}$ and $\mathbf{0}+\mathbf{v}_{\mathbf{8} / \mathbf{9}}^{\mathbf{0}} \rightarrow \mathbf{V}$. The reader is referred to the labeling on Figure 4 and the listing in Table 6 for the other peak assignments. The weak peak at $16,116 \mathrm{~cm}^{-1}$ is assigned to $\mathbf{0} \rightarrow \mathbf{V}+\mathbf{v}^{\mathbf{V}}{ }_{1}$, and the next prominent feature $\sim 40 \mathrm{~cm}^{-1}$ above this transition $\left(16,158 \mathrm{~cm}^{-1}\right)$ is assigned as the $\mathbf{0} \rightarrow \mathbf{V}+\mathbf{v}_{\mathbf{2}} \mathbf{v}_{2}$. The differences in energies of these vibronic bands from the energy of $\mathbf{0}$ $\rightarrow \mathbf{V}$ provides frequencies for $\mathbf{v}_{1} \mathbf{v}_{1}=714 \mathrm{~cm}^{-1}$ and $\mathbf{v}^{\mathbf{v}}{ }_{2}=756 \mathrm{~cm}^{-1}$. The lowering of these frequencies from their values in the ground state is consistent with the LMCT nature of $\mathbf{0} \rightarrow \mathbf{V}$, as previously noted by Denning. ${ }^{15}$ The next sharp features at 16,237, 16,372, and $16,540 \mathrm{~cm}^{-1}$ are assigned as $\mathbf{0} \rightarrow \mathbf{V}+\mathbf{v}^{\mathbf{v}_{8 / 9}}$ $+v^{v_{1}}, 0 \rightarrow V+v^{v_{3 / 6}}+v^{v_{1}}$, and $0 \rightarrow V+v^{v_{3}}+v^{v_{11}}+v^{v_{1}}$ by comparison with the absorption spectrum reported by Denning.

The remaining $\mathbf{0} \rightarrow \mathbf{V}$ structure in Figure 4 from $16,800-18,000 \mathrm{~cm}^{-1}$ is more difficult to assign because vibronic transitions built on $\mathbf{0} \rightarrow \mathbf{V I}$ and $\mathbf{0} \rightarrow$ VII overlap the $\mathbf{0} \rightarrow \mathbf{V}$ transitions. However, several members of progressions in $\boldsymbol{v}_{\mathbf{1}} \mathbf{v}_{\mathbf{1}}\left(\sim 715 \mathrm{~cm}^{-1}\right)$ are evident. The first of these, at $16,872 \mathrm{~cm}^{-1}$, is assigned

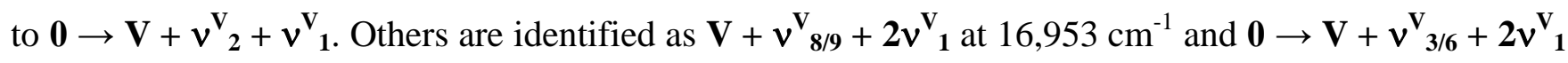
at $17,085 \mathrm{~cm}^{-1}$. The peak at $17,246 \mathrm{~cm}^{-1}$ was assigned by Denning to the overlapping transitions $\mathbf{0} \rightarrow \mathbf{V}$

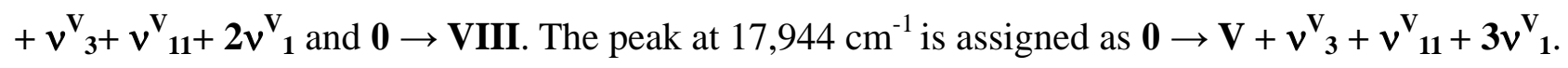

Three transitions belonging $\mathbf{0} \rightarrow \mathbf{V I}$ have also been assigned to a progression in $\mathbf{v}^{\mathbf{V I}}$ built upon $\mathbf{0} \rightarrow \mathbf{V I}$ $+\mathbf{v}_{\mathbf{3} / \mathbf{6}}$. This progression exhibits an average value of $701 \mathrm{~cm}^{-1}$ for $v^{\mathbf{V I}}{ }_{1}$. The region of the spectrum 
above $17,600 \mathrm{~cm}^{-1}$ has been discussed thoroughly in Denning's work as well as our prior report of excitation from $\mathrm{Cs}_{2} \mathrm{U}(\mathrm{Np}) \mathrm{O}_{2} \mathrm{Cl}_{4}$, and will not be reproduced here. ${ }^{14,15,18}$

Figure 4. Laser-induced excitation spectrum between $15,000-18,000 \mathrm{~cm}^{-1}$ recorded while monitoring luminescence from the $\mathbf{I I} \rightarrow \mathbf{0}$ transition of $\mathrm{Cs}_{2} \mathrm{U}(\mathrm{Np}) \mathrm{O}_{2} \mathrm{Cl}_{4}$ at $75 \mathrm{~K}$.

Of particular interest in these spectra is the relation between vibronic peak intensities and changes in the neptunium-oxo bond distance. It is well documented that there are distinct differences expected following intra-5f versus LMCT transitions. It has been shown that the change in neptunium-oxo bond lengths can be estimated using the relative intensities of peaks in vibronic progressions in $v_{1}$ using Equation $1:^{10}$

$$
\Delta R_{N p O} \approx\left[2 S w^{-1} / \omega_{f} m_{O}\right]^{1 / 2}
$$

where $\Delta R_{N p O}$ is the absolute change in the length of the neptunium-oxo bond distance, $S$ is the HuangRhys factor, $\omega_{\mathrm{f}}$ is frequency of $v_{1}$ in the excited electronic state, and $m_{O}$ is the mass of the oxygen atom. The quantity $w$ is the topological factor which takes into account the effective mass in a given molecular symmetry; $w$ is equal to 2 for linear $\mathrm{D}_{\infty \mathrm{h}}$ molecules such as the $[\mathrm{O}-\mathrm{Np}-\mathrm{O}]^{2+}$ moiety. The value of the Huang-Rhys factor value is estimated from the measured relative intensities of the first three members of the $v_{1}$ vibronic progression, which should exhibit the ratios $1: S: S^{2} / 2$. Equation 1 assumes a harmonic approximation without Jahn-Teller distortion or Dushinsky rotations, and does not take into account anharmonicity, change in the vibrational frequency, or vibrational coupling to other modes. Su estimated that Equation 1 should accurately predict changes in bond length to within $10 \%$.

We calculated the change in the neptunium-oxo bond lengths, $\Delta R_{N p O}$, upon excitation into electronic states II - VI using the integrated peak intensity either from our excitation spectra or the absorption spectra of Denning to get values for $\mathrm{S}$ to use in Equation 1. The relative intensity of vibronic bands, Huang-Rhys factor and $\Delta R_{N p O}$ are tabulated in Table 7 along with values for $\Delta R_{N p O}$ calculated using SORASPT2 RASPT2 by Su. ${ }^{10}$ Uncertainties in our $\Delta R_{N p O}$ values were calculated by assuming that the Huang-Rhys factor is accurate to within $20 \%$. Note that for excitations into state IV, the Huang-Rhys factors were calculated using the intensities of vibronic features in the absorption spectra recorded by Denning rather than from our excitation spectrum because the laser power dropped off rapidly to unreliably low levels when approaching the gap seen in Figure 3 from either direction. While peaks could be observed and assigned, their relative intensities do not accurately reflect the true relative transition probabilities. $^{15,25}$ The average change in neptunium-oxo bond length induced by LMCT transitions (IVVI) is $\Delta R_{N p O} \approx 5.4 \pm 1 \mathrm{pm}$, which is in reasonable agreement with the results from the RASPT2 calcula- 
tions $(|\Delta \mathrm{R}|=6.1 \mathrm{pm}) .{ }^{10}$ Using absorption spectra of $\mathrm{Cs}_{2} \mathrm{UO}_{2} \mathrm{Cl}_{4}$, Denning calculated the change in the uranium-oxo bond lengths to be $\Delta R_{U O} \approx 6.5 \mathrm{pm}$ for several LMCT transitions in uranyl using a different method than that described using Equation 1..$^{6,19,21,25,27}$ The average $v_{1}$ energy associated with states IV, $\mathbf{V}$, and VI is $\sim 710 \mathrm{~cm}^{-1}$, considerably lower than the ground state vibrational energy of $v_{1}^{0}\left(802 \mathrm{~cm}^{-1}\right)$ and a weaker neptunium-oxo bond.

We used the same method to estimate the changes in the neptunium-oxo bond lengths from the intra-5f transitions. The results agree reasonably well with calculations using RASPT2 for $\mathbf{0} \rightarrow$ II but not for $\mathbf{0}$ $\rightarrow$ III. The average value of $v_{1}$ for the $5 \mathrm{f} \delta$ and $\phi$ states II and III, $\sim 806 \mathrm{~cm}^{-1}$, is closer in energy to the energy of $\mathbf{v}^{0}{ }_{1}$ in the ground state, and thus it would be predicted that the neptunium-oxo bond length does not change from that of the ground state. The change in neptunium-oxo bond length, $\left|\Delta R_{N p O}\right|$ calculated by RASPT2, predicted that the excitations into states II and III to be 0.8 and 0.3 pm respectively, which is consistent with this prediction. ${ }^{10}$ The changes in the neptunyl bond length derived from the relative intensities of vibronic excitations into the 5 f states (II and III), shown in Table 7, were calculated as well. The $\Delta R_{N p O}$ calculated from the progressions built on $\mathbf{0} \rightarrow \mathbf{I I}$ and $\mathbf{0} \rightarrow \mathbf{I I}+\mathbf{v}^{\mathbf{I I}}{ }_{\mathbf{2}}$ are 0.8 and 1.2 pm, in reasonable agreement with the RASPT2 results. For $\mathbf{0} \rightarrow$ III, however, the intensity ratios are consistent with a significantly larger bond length change, about $2.3 \mathrm{pm}$. While these values for $\Delta R_{N p O}$ are somewhat smaller than those derived from exciting states $\mathbf{I V}, \mathbf{V}$ and $\mathbf{V I}$, they are much larger than the $0.3 \mathrm{pm}$ predicted by the RASPT2 calculations. ${ }^{10}$ One would expect that a $\Delta R_{N p O}$ as large as $\sim 2.3 \mathrm{pm}$ would be accompanied by significant change in $v_{1}$ frequency, whereas essentially no change is observed. The $\triangle R_{N p O}$ values predicted by the RASPT2 calculations $(0.3-0.8 \mathrm{pm})$ would be consistent with values for $S$ that are smaller by a factor of 10 than those derived from the excitation spectrum; this result is well outside the estimated $20 \%$ uncertainty for the Huang-Rhys parameters derived from the data. Currently, we do not have a definitive explanation for the large $\Delta R_{N p O}$ value derived from progression intensities for $\mathbf{0} \rightarrow$ III.

Alternative assignments are plausible for $v_{1}$ progressions built on $\mathbf{0} \rightarrow$ III but these do not improve the agreement with the bond from the RASPT2 calculations. We might consider that the excitation features at $\sim 8,700$ and $9,700 \mathrm{~cm}^{-1}$, assigned to members of $v_{1}$ progressions, could instead be due to the presence of an impurity, but this scenario is not likely because the impurity would have to fluoresce at an energy that is within $\sim 10 \mathrm{~cm}^{-1}$ of the $\mathbf{I I} \rightarrow \mathbf{0}$ transition $\left(6880 \mathrm{~cm}^{-1}\right)$ that was monitored to collect the excitation spectrum. Another possibility is that there is significant interaction between vibronic states that are nearly degenerate, which would invalidate the approximations needed to use Eq. 1. This may warrant further investigation. 
The lack of an observed $\mathbf{0} \rightarrow$ III origin is in agreement with ligand field calculations by Denning which predict no electric or magnetic dipole oscillator strength for the pure electronic transition between the ground electronic state $\mathbf{0}$ and state III, which is in contrast to the $\mathbf{0} \rightarrow$ II for which significant magnetic dipole oscillator strength is predicted. ${ }^{14}$ It is also possible that the origin band for $\mathbf{0} \rightarrow \mathbf{I I I}$ and $\mathbf{0} \rightarrow \mathbf{I I}+$ $\boldsymbol{v}^{\text {III }}{ }_{1}$ are nearly degenerate. As mentioned above, Stone does not observe the $\mathbf{0} \rightarrow$ III origin upon removing the potential degeneracy by substitution with ${ }^{18} \mathrm{O} .{ }^{25}$ However we cannot eliminate the possibility that the $\mathbf{0} \rightarrow \mathbf{I I I}$ is buried in the low-intensity structure near the $\mathbf{0} \rightarrow \mathbf{I I}+\mathbf{V}^{\mathrm{II}}{ }_{1}$. Both the $\mathbf{0} \rightarrow \mathbf{I I}$ and $\mathbf{0} \rightarrow$ III transitions are of the 5f-5f type and might be expected to have similar band structure.

\section{Conclusions}

We report excitation spectra of the intra-5f and LMCT transitions of the $\left[\mathrm{NpO}_{2} \mathrm{Cl}_{4}\right]^{2-}$ anion in $\mathrm{Cs}_{2} \mathrm{U}(\mathrm{Np}) \mathrm{O}_{2} \mathrm{Cl}_{4}$ between 6,600 and $22,000 \mathrm{~cm}^{-1}$. The excitations are tracked by detecting photoluminescence from the $\mathbf{I I} \rightarrow \mathbf{0}$ transition, providing high sensitivity and specificity. Nearly all of the absorption features from Denning's earlier single crystal absorption study are observed in our excitation spectrum, indicating that decay pathways from all higher-lying excited states to the ground state include the $\mathbf{I I} \rightarrow$ 0 transition. The observed vibronic structure includes progressions in the $v_{1}$ symmetric stretching mode of the $5 \mathrm{f}$ states II and III which were not previously reported. Analysis of all $v_{1}$ progression intensities in these transitions as well as in the LMCT transitions produces estimates of the neptunium-oxo bond length changes that are consistent with theoretical results and prior identification of the two types of excited states. 
TABLES

Table 1. Vibrational modes, symmetries in $D_{4 h}$, and ground state vibrational frequencies of $\mathrm{Cs}_{2} \mathrm{NpO}_{2} \mathrm{Cl}_{4} \cdot{ }^{14}$

\begin{tabular}{|l|l|l|}
\hline mode & symmetry in $D_{4 h}$ & vibrational energy $\left(\mathrm{cm}^{-1}\right)$ \\
\hline$v^{0}{ }_{1}$ & $A_{1 g}$ & 802 \\
\hline$v^{0}{ }_{2}$ & $A_{2 u}$ & 919 \\
\hline$v^{0}{ }_{3}$ & $E_{u}$ & 267 \\
\hline$v^{0}{ }_{4}$ & $A_{1 g}$ & 257 \\
\hline$v^{0}{ }_{5}$ & $B_{2 g}$ & 230 \\
\hline$v^{0}{ }_{6}$ & $E_{u}$ & 244 \\
\hline$v^{0}{ }_{7}$ & $B_{1 g}$ & 133 \\
\hline$v^{0}{ }_{8}$ & $E_{u}$ & 117 \\
\hline$v_{9}^{0}$ & $A_{2 u}$ & 117 \\
\hline$v^{0}{ }_{10}$ & $B_{1 u}$ & Raman, infrared inactive \\
\hline$v^{0}{ }_{11}$ & $E_{g}$ & $185 / 190$ \\
\hline
\end{tabular}


Table 2. Excited state, main term, and energy for the ground state and the first 10 electronic states of $\mathrm{Cs}_{2} \mathrm{NpO}_{2} \mathrm{Cl}_{4}$ as reported in references. ${ }^{10,14,15}$

\begin{tabular}{|c|c|c|c|c|c|c|}
\hline \multirow[b]{2}{*}{ state } & \multirow[b]{2}{*}{ type } & \multicolumn{3}{|c|}{ Calculated values from reference 10} & \multicolumn{2}{|c|}{$\begin{array}{l}\text { experimental values from ref- } \\
\text { erences } 14,15\end{array}$} \\
\hline & & main term & energy $\left(\mathrm{cm}^{-1}\right)$ & $v_{1}\left(\mathrm{~cm}^{-1}\right)$ & energy $\left(\mathrm{cm}^{-1}\right)$ & $v_{1}\left(\mathrm{~cm}^{-1}\right)$ \\
\hline $\mathbf{0}$ & $5 f$ & ${ }^{2} \Phi_{u}$ & 0 & 786 & 0 & 802 \\
\hline I & $5 f$ & ${ }^{2} \Delta_{u}$ & 1,055 & 812 & $\sim 1,000$ & 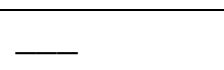 \\
\hline II & $5 f$ & ${ }^{2} \Delta_{u}$ & 5,767 & 809 & $\begin{array}{l}6,880.4 \\
6880^{*}\end{array}$ & $826^{*}$ \\
\hline III & $5 f$ & ${ }^{2} \Phi_{u}$ & 6,658 & 800 & $\sim 7,990 / 7875^{*}$ & $808 *$ \\
\hline IV & LMCT & ${ }^{4} \mathrm{H}_{u}$ & 11,127 & 664 & $\begin{array}{l}13,264.9 \\
13,248^{*}\end{array}$ & $722 / 720^{*}$ \\
\hline $\mathbf{V}$ & LMCT & ${ }^{4} \Sigma_{u}^{-}$ & 14,375 & 665 & $\begin{array}{l}15,406.4 \\
15,402^{*}\end{array}$ & $715 / 714$ \\
\hline VI & LMCT & ${ }^{4} \mathrm{H}_{u}$ & 14,122 & 663 & $\sim 15,683$ & 711 \\
\hline VII & LMCT & ${ }^{4} \Sigma_{u}^{-}$ & 15,330 & 662 & $16,799.8$ & 713 \\
\hline VIII & $5 f$ & - & - & - & $17,241.4$ & - \\
\hline IX & LMCT & ${ }^{4} \Pi_{u}$ & 18,774 & 663 & $19,375.2$ & 686 \\
\hline $\mathbf{X}$ & $5 f$ & $\underline{-}$ & - & 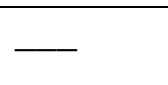 & $20,080.8$ & $\ldots$ \\
\hline
\end{tabular}

*Values from this study 
Table 3. Transition energy, type, frequencies for $v_{1}$ and $v_{2}$.

\begin{tabular}{|l|l|l|l|l|}
\hline transition & type & energy $\left(\mathrm{cm}^{-1}\right)$ & $v_{1}\left(\mathrm{~cm}^{-1}\right)$ & $v_{2}\left(\mathrm{~cm}^{-1}\right)$ \\
\hline II & 5f & 6,880 & 826 & 921 \\
\hline III & $5 f$ & 7,875 & 805 (average) & 922 \\
\hline IV & LMCT & 13,248 & 720 & 760 \\
\hline V & LMCT & 15,402 & 714 & 756 \\
\hline VI & LMCT & & 702 & - \\
\hline
\end{tabular}


Table 4. Assignments of vibronic structure and transition energies for II and III, as well as energies relative to the electronic origin.

\begin{tabular}{|c|c|c|}
\hline transition & energy $\left(\mathrm{cm}^{-1}\right)$ & energy from origin $\left(\mathrm{cm}^{-1}\right)$ \\
\hline $0+v_{8 / 9}^{0} \rightarrow$ II & 6,769 & -111 \\
\hline 0 + lattice modes $\rightarrow$ II & 6,837 & -43 \\
\hline $\mathbf{0} \rightarrow$ II (origin) & 6,880 & 0 \\
\hline o $\rightarrow$ II + lattice modes & 6,923 & 43 \\
\hline $0 \rightarrow \mathrm{II}+v_{8 / 9}^{\text {II }}$ & 7,009 & 129 \\
\hline $0 \rightarrow \mathrm{II}+v_{6}^{\text {II }}$ & 7,126 & 246 \\
\hline $0 \rightarrow \mathrm{II}+v_{3}^{\mathrm{II}}$ & 7,157 & 277 \\
\hline $0 \rightarrow \mathrm{II}+v_{1}$ & 7,706 & 826 \\
\hline $\mathbf{0} \rightarrow \mathrm{II}+\mathrm{v}_{2}^{\mathrm{II}}$ & 7,801 & 921 \\
\hline $0 \rightarrow \mathrm{II}+v_{2}^{\text {II }}+v_{1}^{\text {II }}$ & 8,613 & 1733 \\
\hline $\mathbf{0} \rightarrow$ III (origin) ${ }^{*}$ & 7,875 & 0 \\
\hline $0 \rightarrow \mathrm{III}+v_{8}^{\text {III }}$ & 7,989 & 114 \\
\hline $0 \rightarrow \mathrm{III}+v^{\text {III }}$ & 8,020 & 145 \\
\hline $0 \rightarrow \mathrm{III}+v^{\mathrm{III}}{ }_{6}$ & 8,118 & 243 \\
\hline 0 $\rightarrow$ III $+v_{3}^{\text {III }}$ & 8,143 & 268 \\
\hline $\begin{array}{l}0 \rightarrow \text { III }+v^{\text {III }}+v^{\text {III }}{ }_{1} \text { or } 0 \rightarrow \text { III } \\
+v^{\text {III }}\end{array}$ & 8,797 & 922 \\
\hline $0 \rightarrow$ III $+v_{9}^{\text {III }}+v_{1}^{\text {III }}$ & 8,830 & 955 \\
\hline $\begin{array}{l}\text { 0 } \rightarrow \text { III }+v^{\text {III }}+2 v_{1}^{\text {III }} \text { or } 0 \rightarrow \\
\text { III }+v_{2}^{\text {III }}+v_{1}^{\text {III }}\end{array}$ & 9,593 & 1718 \\
\hline $0 \rightarrow$ III $+v^{\text {III }}+2 v^{I I I}{ }_{1}$ & 9,635 & 1760 \\
\hline
\end{tabular}

*Energy estimated, see text. 
Table 5. Assignments of vibronic structure and transition energies for $\mathbf{I V}$, as well as energies relative to the electronic origin.

\begin{tabular}{|c|c|c|}
\hline transition & energy $\left(\mathrm{cm}^{-1}\right)$ & energy from origin $\left(\mathrm{cm}^{-1}\right)$ \\
\hline $0+v_{8 / 9}^{0} \rightarrow I V$ & 13,133 & -115 \\
\hline o + lattice modes $\rightarrow$ IV & 13,210 & -38 \\
\hline $\mathbf{0} \rightarrow \mathbf{I V}$ (origin) & 13,248 & 0 \\
\hline $0 \rightarrow$ IV + lattice modes & 13,282 & 34 \\
\hline $0 \rightarrow \mathrm{IV}+v^{\mathrm{IV}} 8 / 9$ & 13,352 & 104 \\
\hline $0 \rightarrow I V+v^{I V}{ }_{6}$ & 13,486 & 238 \\
\hline $0 \rightarrow I V+v^{I V}$ & 13,497 & 249 \\
\hline $0 \rightarrow \mathrm{IV}+\mathrm{v}^{\mathrm{IV}}$ & 13,968 & 720 \\
\hline $0 \rightarrow I V+v_{2}^{I V}$ & 14,008 & 760 \\
\hline $0 \rightarrow I V+v_{8 / 9}^{I V}+v_{1}^{I V}$ & 14,074 & 826 \\
\hline $0 \rightarrow I V+v^{I V}+v^{I V}$ & 14,726 & 1478 \\
\hline
\end{tabular}


Table 6. Assignments of vibrionic structure and transition energies for $\mathbf{V}$ and $\mathbf{V I}$, as well as energies relative to the electronic origin.

\begin{tabular}{|c|c|c|}
\hline transition & energy $\left(\mathrm{cm}^{-1}\right)$ & $\begin{array}{l}\text { energy from origin }\left(\mathrm{cm}^{-}\right. \\
1^{-}\end{array}$ \\
\hline $0+v_{8 / 9}^{0} \rightarrow V$ & 15,284 & -118 \\
\hline $\mathbf{0}+$ lattice modes $\rightarrow V$ & 15,355 & -47 \\
\hline $\mathbf{0} \rightarrow \mathbf{V}$ (origin) & 15,402 & 0 \\
\hline $\mathbf{0} \rightarrow \mathrm{V}+$ lattice modes & 15,449 & 47 \\
\hline $0 \rightarrow V+v_{8 / 9}^{V_{1}}$ & 15,525 & 123 \\
\hline $0 \rightarrow V+v_{6}$ & 15,613 & 211 \\
\hline $\mathbf{0} \rightarrow \mathbf{V}+v_{3}^{v_{3}}$ & 15,654 & 252 \\
\hline $0 \rightarrow V+v_{3}+v_{11}^{V}$ & 15,822 & 420 \\
\hline $0 \rightarrow V+v_{1}^{V_{1}}$ & 16,116 & 714 \\
\hline $\mathbf{0} \rightarrow \mathbf{V}+v_{2}^{v_{2}}$ & 16,158 & 756 \\
\hline $0 \rightarrow V+v_{8 / 9}^{V_{19}+v_{1}}$ & 16,237 & 835 \\
\hline $0 \rightarrow V+v_{3 / 6}^{V_{1}}+v_{1}^{V_{1}}$ & 16,372 & 970 \\
\hline$\underset{v_{1}}{\mathbf{0}} \rightarrow \mathrm{V}+v_{3}^{v_{3}+v_{11}} v_{1}+v$ & 16,540 & 1,138 \\
\hline $0 \rightarrow V+v_{2}^{v_{2}}+v_{1}^{V_{1}}$ & 16,872 & 1,470 \\
\hline $0 \rightarrow V+v_{8 / 9}^{V_{1}}+2 v_{1}$ & 16,953 & 1,551 \\
\hline $0 \rightarrow V+v_{3 / 6}^{v}+2 v_{1}^{v}$ & 17,085 & 1,683 \\
\hline $\begin{array}{l}0 \rightarrow V+v_{3}^{v_{3}+v_{11}+} \\
v^{v_{1}} \text { or } 0 \rightarrow \text { VIII (ori- } \\
\text { gin) }\end{array}$ & 17,246 & 1,844 \\
\hline $\begin{array}{l}0 \underset{3 v_{1}}{\rightarrow} \mathrm{V}+v_{3}^{v_{3}}+v_{11}^{v_{11}}+ \\
\text {. }\end{array}$ & 17,944 & 2,542 \\
\hline $0 \rightarrow V I+v_{3 / 6}^{V}$ & 15,917 & - \\
\hline $0 \rightarrow V I+v_{3 / 6}^{V_{3 / 6}}+v^{V_{1}}$ & 16,623 & - \\
\hline $0 \rightarrow V I+v_{3 / 6}^{V}+2 v_{1}^{V}$ & 17,321 & - \\
\hline
\end{tabular}


Table 7. Vibronic progressions based on $v_{1}$ observed in the excitation spectra, the relative intensity of these bands to $x=0$, the Huang-Rhys parameter $(S)$, and the absolute change in the neptunium-oxo bond distance $(\Delta \mathrm{R})$ derived from Equation 1. Units on $\Delta \mathrm{R}$ are pm. Uncertainties are obtained assuming that the Huang-Rhys parameter is correct to within $20 \%$ of its value. The subscripts in the notation $S_{0 x}$ and $\Delta \mathrm{R}_{0 \mathrm{X}}$ refer to the vibrational quantum numbers from which the value is derived. The value for $\Delta \mathrm{R}_{\mathrm{ave}}$ is simply the average value of the derived bond length change.

\begin{tabular}{|c|c|c|c|c|c|c|c|c|c|}
\hline transition & $\mathrm{x}=0$ & $x=1$ & $x=2$ & $\mathrm{~S}_{01}$ & $\mathrm{~S}_{02}$ & $\Delta \mathrm{R}_{01}$ & $\Delta \mathrm{R}_{02}$ & $\Delta \mathrm{R}_{\mathrm{ave}}$ & $|\Delta \mathrm{R}|^{10}$ \\
\hline $0 \rightarrow \mathrm{II}+\mathrm{x} v^{\mathrm{II}}{ }_{1}$ & 1.00 & 0.03 & - & 0.03 & --- & 0.9 & - & $0.9(0.3)$ & -0.8 \\
\hline $0 \rightarrow \mathrm{II}+v_{2}^{\mathrm{II}}+\mathrm{x} v^{\mathrm{II}}{ }_{1}$ & 1.00 & 0.06 & - & 0.06 & - & 1.2 & - & $1.2(0.3)$ & -0.8 \\
\hline$* 0 \rightarrow \mathrm{III}+v_{8}^{\mathrm{III}}+\mathrm{x} v_{1}^{\mathrm{III}}$ & 1.00 & 0.17 & 0.03 & 0.17 & 0.2 & 2.1 & 2.5 & $2.3(0.6)$ & 0.3 \\
\hline$* 0 \rightarrow \mathrm{III}+v_{2}^{\mathrm{III}}+\mathrm{x} v_{1}^{\mathrm{III}}$ & 1.00 & 0.18 & - & 0.18 & - & 2.2 & 一 & $2.2(0.6)$ & 0.3 \\
\hline $0 \rightarrow \mathrm{III}+v_{9}^{\mathrm{III}}+\mathrm{x} v^{\mathrm{III}}$ & 1.00 & 0.16 & 0.03 & 0.16 & 0.2 & 2.0 & 2.5 & $2.3(0.5)$ & 0.3 \\
\hline $0 \rightarrow \mathrm{IV}+v_{2}^{\mathrm{IV}}+\mathrm{x} v^{\mathrm{IV}}{ }_{1}$ & 1.00 & 0.83 & 0.40 & 0.83 & 0.9 & 4.9 & 5.1 & $5.0(1.0)$ & 6.4 \\
\hline $0 \rightarrow \mathrm{IV}+v^{\mathrm{IV}}{ }_{8 / 9}+\mathrm{x} v_{1}^{\mathrm{IV}}$ & 1.00 & 0.86 & 0.41 & 0.86 & 0.9 & 5.0 & 5.2 & $5.1(1.0)$ & 6.4 \\
\hline $0 \rightarrow \mathrm{V}+v_{8 / 9}^{\mathrm{V}}+\mathrm{x} v_{1}^{\mathrm{V}}$ & 1.00 & 1.03 & 0.85 & 1.03 & 1.3 & 5.5 & 6.2 & $5.9(1.0)$ & 6.3 \\
\hline $0 \rightarrow \mathrm{V}+v_{3 / 6}^{\mathrm{V}}+\mathrm{x} v_{1}^{\mathrm{V}}$ & 1.00 & 1.12 & 0.60 & 1.12 & 1.1 & 5.8 & 5.7 & $5.8(1.0)$ & 6.3 \\
\hline $\begin{array}{l}0 \rightarrow \mathrm{V}+\mathrm{v}_{3}{ }_{3}+v_{11}^{\mathrm{V}}+ \\
\mathrm{x} v_{1}^{\mathrm{V}}\end{array}$ & 1.00 & 0.95 & 0.74 & 0.95 & 1.2 & 5.3 & 6.0 & $5.7(1.0)$ & 6.3 \\
\hline $0 \rightarrow \mathrm{VI}+v_{3 / 6}^{\mathrm{VI}}+\mathrm{x} v_{1}^{\mathrm{VI}}$ & 1.00 & 0.82 & 0.26 & 0.82 & 0.7 & 4.9 & 4.6 & $4.8(1.0)$ & 5.4 \\
\hline
\end{tabular}

*For alternative assignments, see text.

NOTE: $\Delta \mathrm{R}$ for $\mathbf{0} \rightarrow \mathbf{I V}+\mathbf{v}_{\mathbf{2}}^{\mathrm{IV}}+\mathbf{x} \mathbf{v}_{\mathbf{1}}^{\mathrm{IV}}$ and $\mathbf{0} \rightarrow \mathbf{I V}+\mathbf{v}_{\mathbf{8 / 9}}^{\mathrm{IV}}+\mathbf{x} \mathbf{v}^{\mathrm{IV}}{ }_{\mathbf{1}}$ were determined using intensities from Denning's absorption spectra. ${ }^{15}$ 


\section{AUTHOR INFORMATION}

\section{Corresponding Author}

* E-mail: mpw@lanl.gov. Phone: (505) 667-5922. Fax: (505) 665-4955.

\section{Notes}

The authors declare no competing financial interests.

\section{ACKNOWLEDGMENT}

This material is based upon work supported by the U.S. Department of Energy, Office of Science, Office of Basic Energy Science. Los Alamos National Laboratory is managed and operated by Los Alamos National Security, LLC (LANS), under contract number DE-AC52-06NA25396 for the U.S. Department of Energy's National Nuclear Security Administration (NNSA). B. J. B. gratefully acknowledges a LANL Seaborg Institute Fellowship. N. R. W. gratefully acknowledges support from the LANL LDRD program office.

\section{REFERENCES}

1. Matsika, S.; Pitzer, R. M. J. Phys. Chem. A. 2000, 104, 4064-4068.

2. Matsika, S.; Pitzer, R. M. J. Phys. Chem. A. 2001, 105, 637-645.

3. Matsika, S.; Zhang, Z.; Brozell, S. R.; Blaudeau, J. -P.; Wang, Q.; Pitzer, R. M. J. Phys. Chem. A. 2001, 105, 3825-3828.

4. Pierloot, K.; van Besien, E. J. Chem. Phys. 2005, 123, 204309-1-10.

5. Infante, I.; Gomes, A. S. P.; Visscher, L. J. Chem. Phys. 2006, 125, 074301-1-8.

6. Denning, R. G. J. Phys. Chem. A. 2007, 111, 4125-4143.

7. Liu, G. K.; Jensen, M. P. Chem. Phys. Lett. 2010, 499, 178-181.

8. Liu, G.; Wang, S.; Albrecht-Schmitt, T. E.; Wilkerson, M. P. J. Phys. Chem. A. 2012, 116, 82978202.

9. Natrajan, L. S. Coord. Chem. Rev. 2012, 256, 1583-1603.

10. Su, J.; Schwarz, W. H. E.; Li, J. Inorg. Chem. 2012, 51, 3231-3238.

11. Neidig, M. L.; Clark, D. L.; Martin, R. L. Coord. Chem. Rev. 2013, 257, 394-406.

12. Mizuoka, K.; Tsushima, S.; Hasegawa, M.; Hoshi, T.; Ikeda, Y. Inorg. Chem. 2005, 44, 6211-6218.

13. Grossman, K.; Arnold, T.; Ikeda-Ohno, A.; Steudtner, R.; Geipel, G.; Bernhard, G. Spectrochim. Acta, Part A 2009, 72, 449-453.

14. Denning, R. G.; Norris, J. O. W.; Brown, D. Mol. Phys. 1982, 46, 287-323.

15. Denning, R. G.; Norris, J. O. W.; Brown, D. Mol. Phys. 1982, 46, 325-364.

16. Wilkerson, M. P.; Berg, J. M.; Hopkins, T. A.; Dewey, H. J. J. Solid State Chem. 2005, 178, 584-588. 
17. Wilkerson, M. P.; Arrington, C. A.; Berg, J. M.; Scott, B. L. J. Alloys Compd. 2007, 444-445, 634639.

18. Wilkerson, M. P.; Berg, J. M. Radiochim Acta. 2009, 97, 223-226.

19. Stafsudd, O. M.; Leung, A. F.; Wong, E. Y. Phys. Rev. 1969, 180, 339-343.

20. Gorshkov, N. G.; Ladygin, I. N.; Mashirov, L. G.; Suglobov, D. N. Radiokhimiya. 1975, 17, 896899.

21. Denning, R. G.; Snellgrove, T. R.; Woodwark, D. R. Mol. Phys. 1976, 32, 419-442.

22. Denning, D. R.; Snellgrove, T. R.; Woodwark, D. R. Mol. Phys. 1979, 37, 1109-1143.

23. Denning, D. R. Struct. Bond. 1992, 79, 215-276.

24. Handbook of Basic Atomic Spectroscopic Data; National Institute of Standards and Technology, http://www.nist.gov.

25. Stone, P. J. Ph.D. Thesis, University of Oxford, 1985.

26. Su, J.; Wei, F.; Schwarz, W. H.; Li, J. J. Phys. Chem. A 2012, 116, 12299-12304.

27. Barker, T. J.; Denning, R. G.; Thorne, J. R. G. Inorg. Chem. 1987, 26, 1721-1732. 


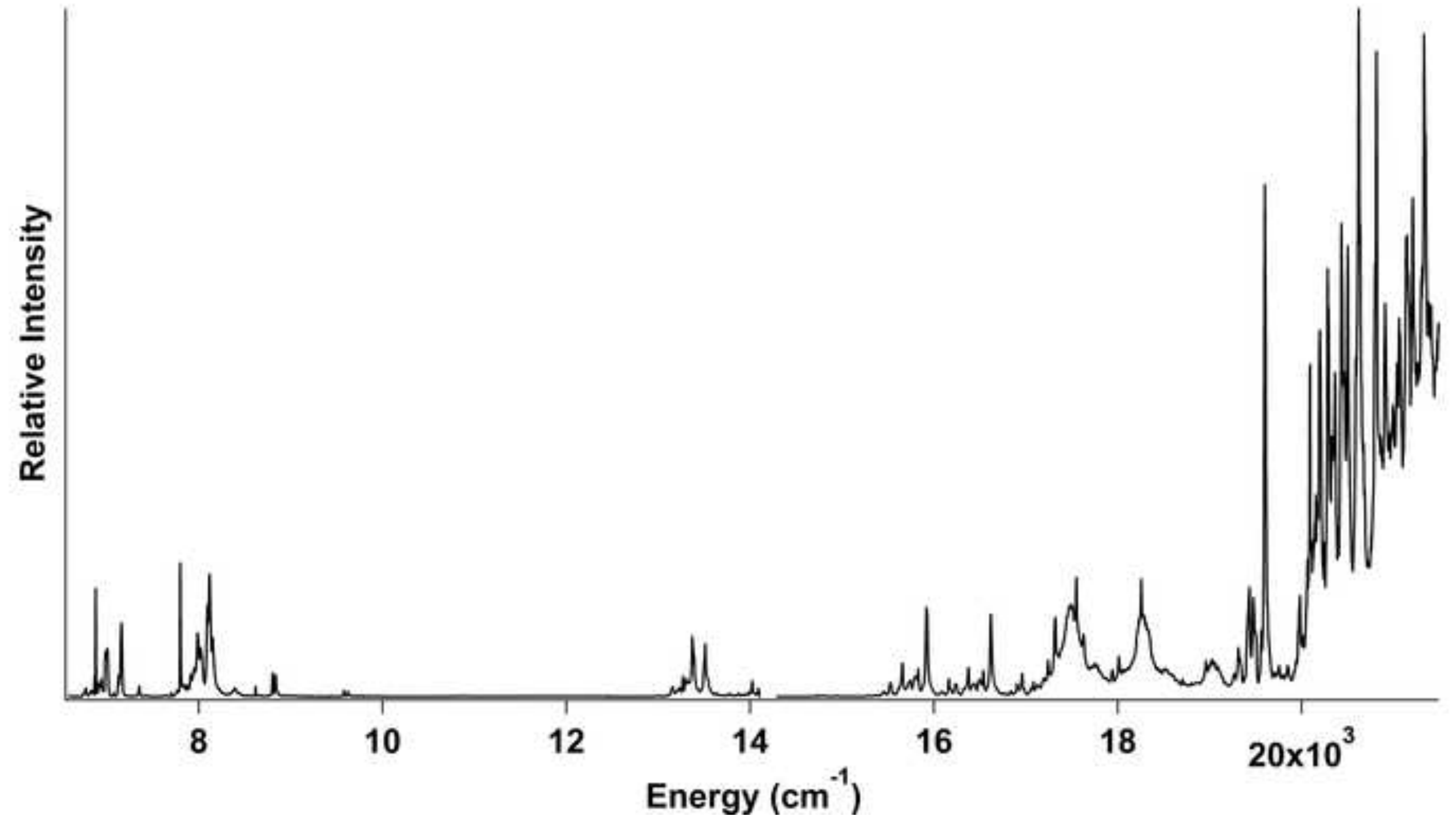




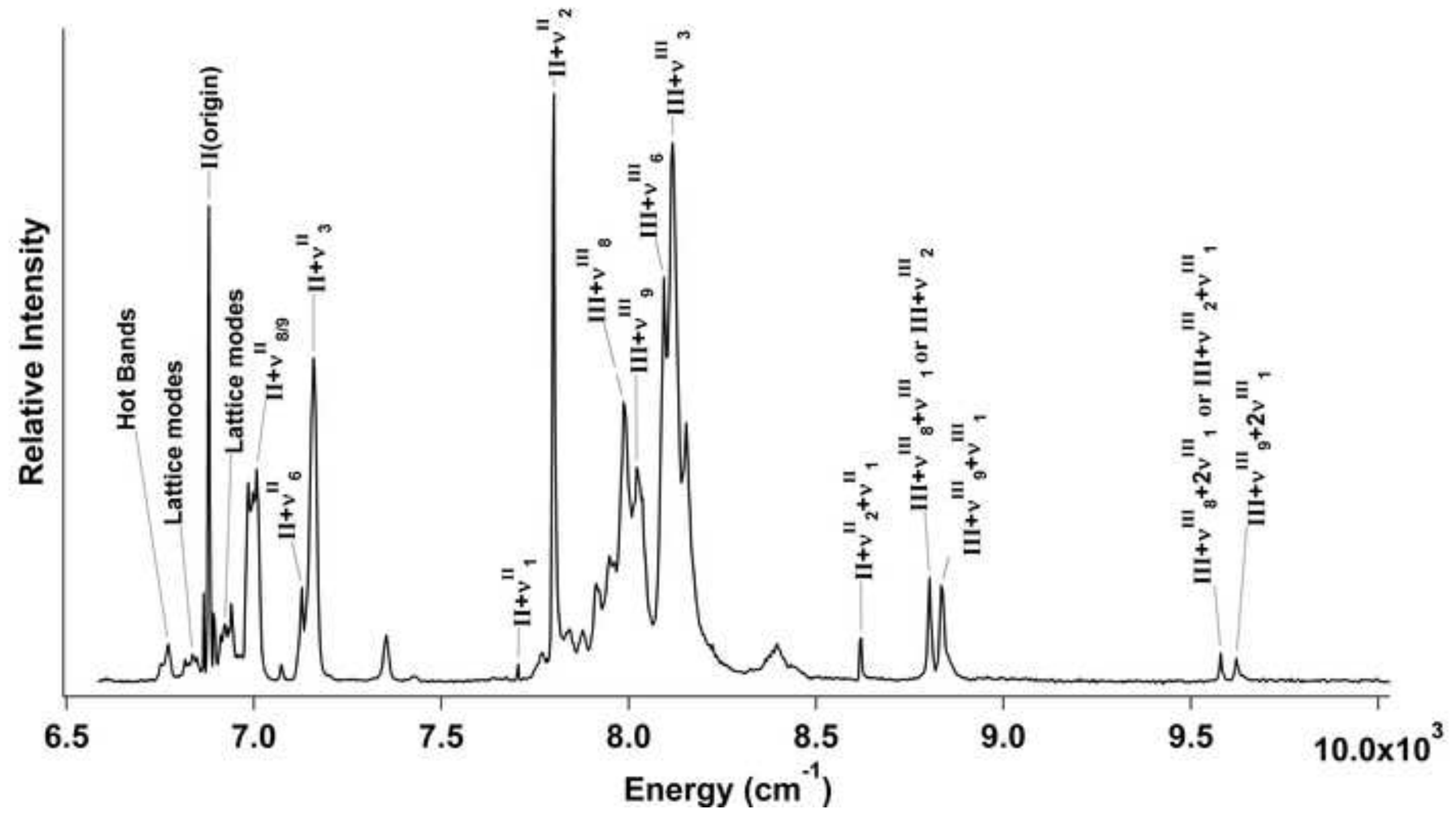




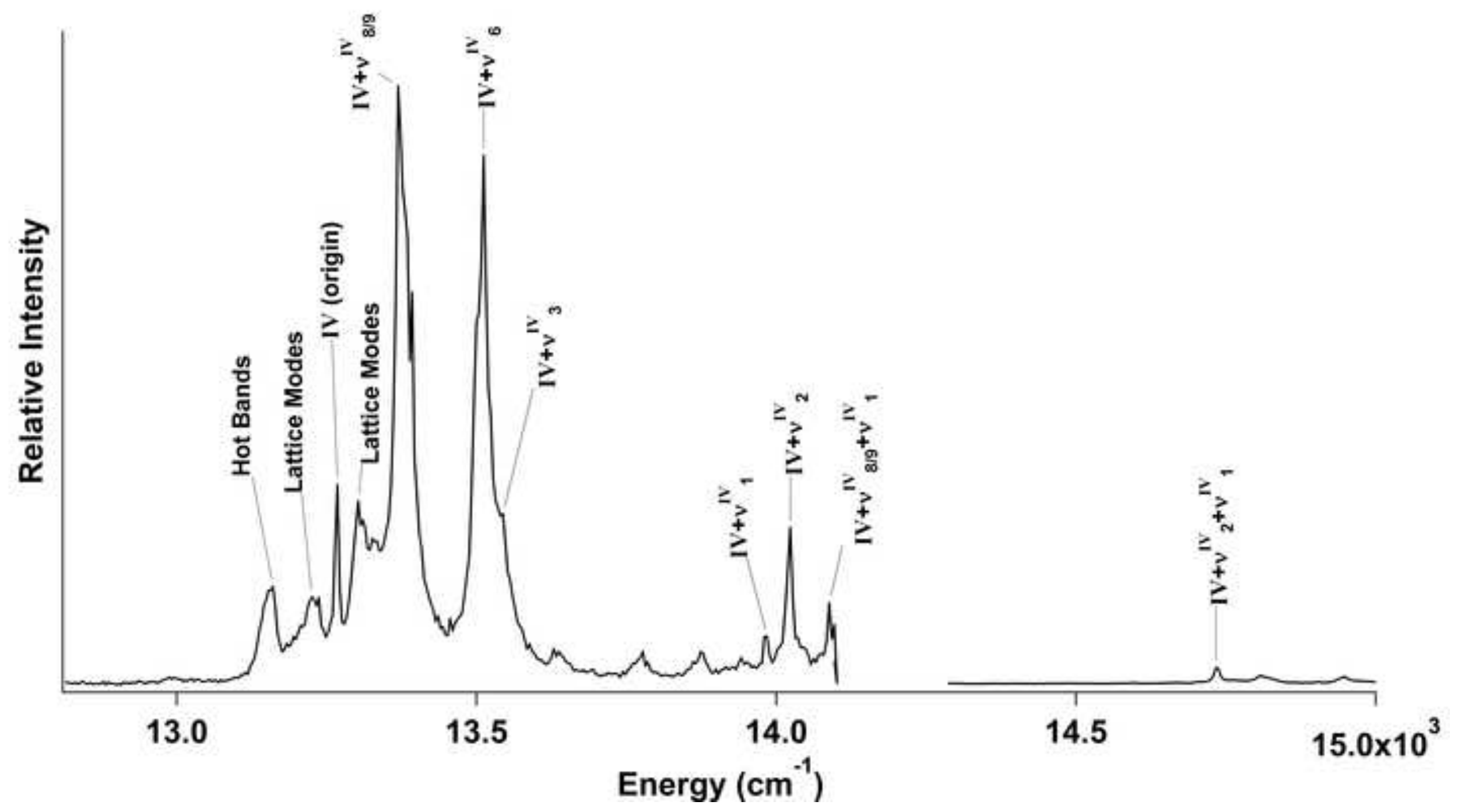




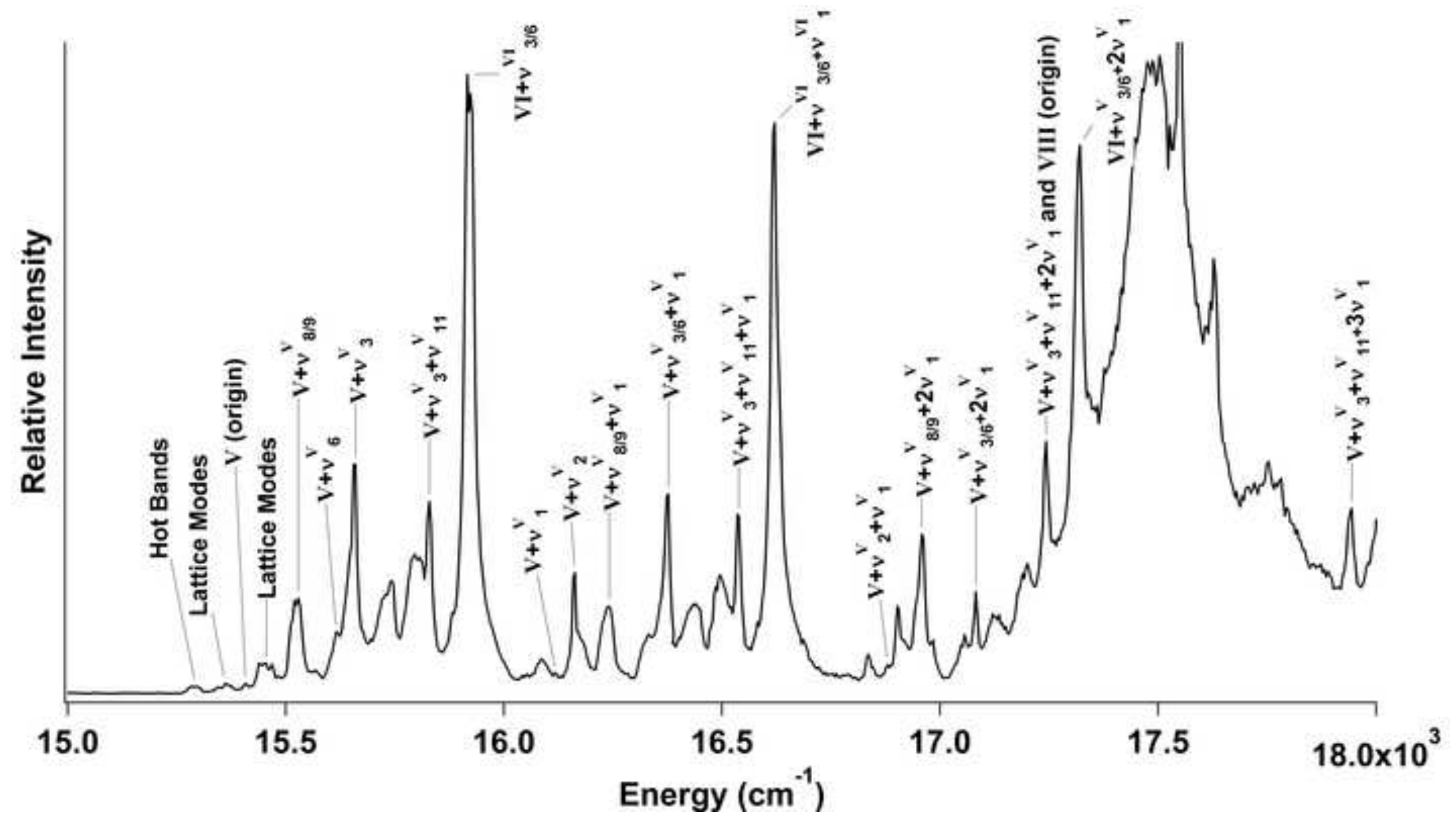


